\title{
Assessment of dosimetric parameters in mammography employing a homemade ionization chamber
}

\author{
Estimativa de parâmetros dosimétricos em mamografia utilizando uma câmara de ionização
} caseira

\author{
J. O. Silva ${ }^{1,2 *} ;$ L. V. E. Caldas ${ }^{2}$ \\ ${ }^{1}$ Instituto de Física, Universidade Federal de Goiás, 74001-970, Goiânia/GO, Brasil \\ ${ }^{2}$ Instituto de Pesquisas Energéticas e Nucleares, Comissão Nacional de Energia Nuclear, 05508-000, São Paulo/SP, \\ Brasil
}

jonas.silva@ufg.br

(Recebido em 15 de julho de 2016; aceito em 13 de outubro de 2016)

\begin{abstract}
A mamografia é a ferramenta de referência para detectar o câncer de mama num estágio inicial. O programa de controle de qualidade do mamógrafo deve abranger tanto a proteção radiológica do paciente quanto do corpo técnico. As câmaras de ionização de placas paralelas são os detectores de referência para dosimetria em mamografia, mas representam um custo elevado para clínicas de pequeno porte em países como o Brasil. Neste trabalho, é apresentada uma câmara de ionização de baixo custo desenvolvida no IPEN para dosimetria na faixa de energia de raios X em mamografia. Esta câmara tem um volume sensível de $6 \mathrm{~cm}^{3}$ e foi utilizada para realizar testes de controle de qualidade em dois mamógrafos: um GE Senographe DMR-plus e um Philips VMI Graph Mammo. As montagens experimentais seguiram os relatórios da IAEA HHS $\mathrm{n}^{\circ} 2$ e $\mathrm{n}^{\circ}$ 17. Um objeto simulador de mama com várias espessuras de PMMA foi utilizado neste trabalho. O desempenho da câmara de ionização caseira foi comparado com o de uma câmara comercial. A diferença entre o kerma no ar incidente medido com a câmara de ionização de referência e com a desenvolvida foi de 5,62\% para o equipamento GE e 4,42\% para o equipamento Philips. A câmara de ionização caseira apresentou um excelente desempenho tanto nas medições do kerma no ar incidente quanto nas medições da CSR para as técnicas radiográficas utilizadas neste trabalho. Todos os resultados obtidos neste trabalho estavam de acordo com as especificações da IAEA.

Palavras-chave: mamografia, câmara de ionização, dose glandular média
\end{abstract}

$\mathrm{X}$-ray mammography examination is the reference tool to discover breast cancer in an early stage. The mammography unit must follow an accurate quality control program that covers both patient and staff radiation protection. Plane parallel ionization chambers are the reference instrument for dosimetry in mammography beams, but they can represent a higher cost for small clinics in countries as Brazil. In this work, it is presented a low-cost ionization chamber for mammography X-rays energy range dosimetry developed at IPEN. The homemade ionization chamber has a sensitive volume of $6.0 \mathrm{~cm}^{3}$ and it was utilized to execute quality control tests in two distinct mammography systems: a GE Senographe DMR-plus and a Philips VMI Graph Mammo. The setups for the tests performed agreed with the IAEA HHS 2 and 17 recommendations. A breast phantom of various PMMA thicknesses was utilized in this work. The homemade ionization chamber performance was compared to that of a commercial one. The maximum difference between the incident air kerma measured with the reference ionization chamber and the developed one was only $5.62 \%$ for the GE equipment and only $4.42 \%$ for the Philips equipment. The homemade ionization chamber presented an excellent performance in incident air kerma and HVL measurements for the radiographic techniques utilized in the present work. All the results obtained were within IAEA specifications.

Keywords: mammography, ionization chamber, mean glandular dose

\section{INTRODUCTION}

The predominant source of population exposition to ionizing radiation comes from medical equipment as CT scans and conventional and digital X-ray machines [1]. The diagnosis based on ionizing radiation examinations brings benefits to patients undergoing these procedures, as a correct medical treatment when the various characteristics of the disease are revealed. Some kinds 
of diseases, as breast cancer, have a favorable prognosis when detected in early stages. The way to achieve it is by X-ray mammography examination that is an important tool for the tumor detection and localization [2]. In 2012, 1.7 million new cases of breast cancer were estimated around the world [3]. In Brazil, this kind of neoplasia is the principal one that afflicts women, excluding non-melanoma skin cancer, and nearly 58,000 new occurrences are probable to happen in 2016 [4].

To ensure the quality necessary for a precise diagnostic, the X-ray mammography unit must follow an accurate quality control program that covers both patient and staff radiation protection. Radiation dosimetry in mammography screening plays an essential role to guarantee the procedure quality that has to be subjected to international recommendations [5]. In fact, the goal of dosimetry in mammography is to evaluate if the mean glandular dose $\left(\mathrm{D}_{\mathrm{G}}\right)$ reflects the compromise between the high diagnostic image quality and the lowest patient dose [6]. $\mathrm{D}_{\mathrm{G}}$ values are calculated with incident air kerma values and with tabulated conversion coefficients that are half value layer (HVL) dependent. These parameters (incident air kerma and HVL) should be acquired with reliable dosimeters, as ionization chambers. Plane-parallel ionization chambers are the reference ionizing radiation detectors in mammography beams dosimetry because they present low energy dependence in the mammography beams and low perturbation of the radiation field [7].

In Brazil, commercial ionization chambers acquisition can be a financial challenge for various diagnostic clinics due to their high cost; therefore, a Brazilian research institute (IPEN), have developed low-cost ionization chambers with national technology and high metrological level for clinical and calibration purposes [8-11]. In an anterior paper [12] a Tandem ionization chamber was utilized for some quality control tests in mammography energy range, but only for radiographic techniques applied to some PMMA equivalent breasts.

The aim of this investigation was to measure the incident air kerma and HVL to calculate the $\mathrm{D}_{\mathrm{G}}$ in two distinct mammography systems with a homemade ionization chamber developed at IPEN [11]. To accomplish this, the homemade ionization chamber was previously calibrated at the Calibration Laboratory of IPEN (LCI/IPEN) in the mammography energy range (standard beams). The quantities determined with this ionization chamber in a clinical environment were compared to those obtained with a commercial ionization chamber, showing its possible use as an alternative choice for dosimetry for a mammography quality control program.

\section{MATERIALS AND METHODS}

The homemade ionization chamber (called HIC in this work) was described and characterized previously in mammography standard radiation beams [11]. It presents an adequate energy dependence response in the whole mammography energy range and is $2.0 \mathrm{~cm}$ thick, which is an important characteristic for thin breast dosimetry without the need of ionization chamber thickness corrections. To perform the readings and for polarization potential, the HIC was connected to a PTW UNIDOS electrometer. During the experiments, the HIC was polarized with $+300 \mathrm{~V}$, and the ionization current was measured. In Figure 1 a photo of the HIC, including its dimensions, is presented. The results obtained with the HIC were compared with ones obtained with a reference dosimetry system formed by a Radcal $10 \mathrm{X} 5-6 \mathrm{M}$ ionization chamber and a Radcal 9015 electrometer, calibrated at the LCI/IPEN.

Two mammography units were used to perform this investigation. The first one was a GE Senographe DMR-plus system with a molybdenum/rhodium target and molybdenum/rhodium/aluminum filters. This mammography unit allows a tube tension range from $20 \mathrm{kV}$ to $49 \mathrm{kV}$, and it has an inherent filtration of $0.69 \mathrm{mmBe}$. A Philips VMI Graph Mammo AF system with a molybdenum target and molybdenum/rhodium filters was used too. This equipment allows the tube tension range from $10 \mathrm{kV}$ to $35 \mathrm{kV}$, and has an inherent filtration of $0.5 \mathrm{mmBe}$.

For all tests performed in this work, the ionization chamber was positioned in the center of the $X$-ray field as stated in international reports [6,15]. Corrêa et al. [13] evaluated the dose distribution in an X-ray field generated by a mammography system and they found that the 
highest dose was about $50 \mathrm{~mm}$ from the chest wall. So, the ionization chambers utilized in this work had their sensitive volume center located at this position for all radiation equipment employed in the current investigation, instead of the common distance of $40 \mathrm{~mm}$. The breast phantom used in this work was developed at IPEN [14], and it is based on TRS 457 report [16]. It consists of various PMMA slabs in a semicircle shape with $200 \mathrm{~mm}$ in diameter and $5 \mathrm{~mm}$ in thickness. An illustration of this phantom is presented in Figure 2.

Figure 1: The HIC presented as a photo (a) and as a drawing (b)

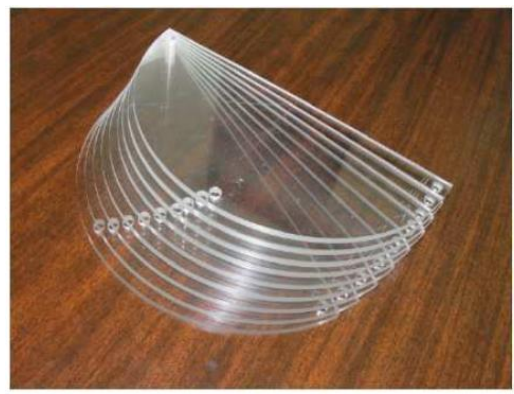

(a)

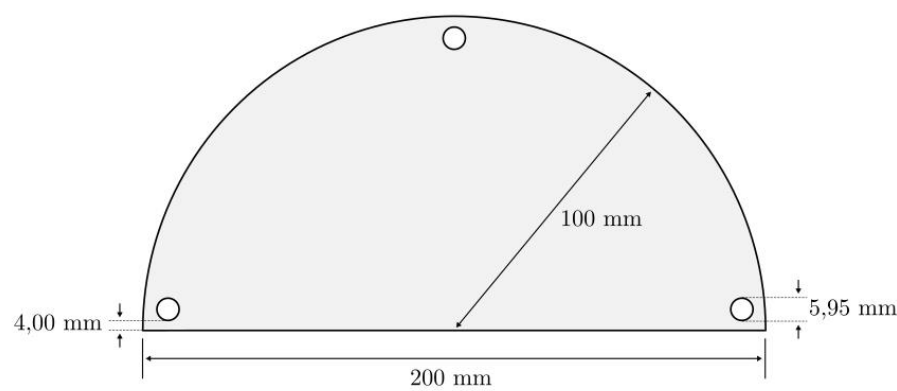

(b)

Figure 2:(a) Breast phantom utilized in this work. (b) Drawing of a phantom slab presenting its dimensions (modified from [14])

\subsection{Beam output repeatability and linearity}

For this test, the HIC was located at $10 \mathrm{~cm}$ from the breast support in the radiation field, without the breast compression device. The radiographic technique utilized in this test was a tube tension of $28 \mathrm{kV}$ and Mo/Mo target-filter combination, for 20,40 , and $80 \mathrm{mAs}$ of the current-time product. For each set of the tube tension and current-time product, it was obtained the average value of five consecutive measurements of the incident air kerma. The output repeatability was obtained with the coefficient of variation (COV) as defined in IAEA HHS report No 2 [6]:

$$
\operatorname{COV}=\frac{\bar{\sigma}_{x}}{\bar{x}}
$$

where $\bar{\sigma}_{x}$ is the standard deviation of a set of five measurements and $\bar{x}$ is their mean value.

The beam output $\mathrm{Y}$ was determined by [6]:

$$
Y=\frac{\bar{K}_{a}}{m A s}
$$

where $\bar{K}_{a}$ is the mean incident air kerma value for the related current-time product. With the output values, the beam output linearity was calculated by [6]:

$$
L=100 \frac{\left(Y_{1}-Y_{2}\right)}{\left(Y_{1}+Y_{2}\right)}
$$

where $Y_{1}$ and $Y_{2}$ are the output values for the specific mAs values. The normalized output was obtained with the product between the output average values and the correction factor for $100 \mathrm{~cm}$. 
The incident air kerma values were determined by placing the ionization chamber at the same position of the phantom but without it. To accomplish this, for each phantom thickness $(20 \mathrm{~cm}, 45 \mathrm{~cm}, 60 \mathrm{~cm}$, and $80 \mathrm{~cm})$ the irradiation parameters were obtained (mAs and $\mathrm{kV})$ in the automatic mode. Afterward, the ionization chamber was set at the equal position of the phantom, and it was irradiated with the same parameters as obtained in the automatic mode for the PMMA slabs, without the breast compression device. The incident air kerma for the correspondent PMMA thickness was calculated by [6]:

$$
K_{i, t}=M_{C} N_{k} k_{T, p}
$$

where $\mathrm{M}_{\mathrm{C}}$ is the ionization chamber reading, $\mathrm{N}_{\mathrm{k}}$ is the ionization chamber calibration factor, and $\mathrm{k}_{\mathrm{T}, \mathrm{p}}$ is the temperature and pressure correction factor for the reference conditions.

\subsection{Half-value layer determination}

In this test, many aluminum layers with $99.99 \%$ purity were utilized to determine the HVL of the X-ray beams employed in this work. These layers were placed at the breast compression device in the middle of the distance between the ionization chamber and the X-ray tube focus. The ionization chamber position was changed to correspond to breasts with different thicknesses named thin, intermediate, and thick. The filter-target combination utilized in this test was Mo/Mo for thin and intermediate breasts and $\mathrm{Mo} / \mathrm{Rh}$ for thick ones. For each set of aluminum layers, the average value of five measurements was accounted. For mammography energy range, the HVL is calculated using [6]:

$$
H V L=\frac{t_{1} \ln \left[2 M_{1} / M_{0}\right]-t_{2} \ln \left[2 M_{2} / M_{0}\right]}{\ln \left[M_{1} / M_{2}\right]}
$$

where $\mathrm{M}_{0}$ is the average value of the measurements obtained without the aluminum layers, $\mathrm{M}_{1}$ and $\mathrm{M}_{2}$ are the measurements, respectively, just above and just below $50 \%$ of $\mathrm{M}_{0}$, and $\mathrm{t}_{1}$ and $\mathrm{t}_{2}$ are the thicknesses of the aluminum layers.

\subsection{Determination of $\mathrm{D}_{\mathrm{G}}$}

$D_{G}$ values were calculated with the results obtained from the incident air kerma for specific breast phantom thickness $\left(\mathrm{K}_{\mathrm{i}, \mathrm{t}}\right)$ and from conversion coefficients obtained in the IAEA HHS report No 17 [15], that are HVL dependent. For the mean glandular dose determination the following expression was applied [15]:

$$
D_{G}=g_{t} c_{t} s K_{i, t},
$$

where $\mathrm{g}_{\mathrm{t}}$ is the conversion coefficient that transforms the incident air kerma into $\mathrm{D}_{\mathrm{G}}$ for a breast with $50 \%$ composition of glandular tissue with a thickness of $t \mathrm{~mm}, \mathrm{c}_{\mathrm{t}}$ is the conversion coefficient that corrects the difference in composition of typical breasts from 50\% glandular of thickness $t \mathrm{~mm}, s$ is the conversion factor that takes into account the anode/filter combination used [16-18] and $\mathrm{K}_{\mathrm{i}, \mathrm{t}}$ is the calculated incident air kerma without the PMMA slabs utilized to represent the standard breast with a thickness $t$. The $g_{t}, c_{t}$, and $s$ values are reported in the IAEA HHS No 17 report [15]. 


\section{RESULTS AND DISCUSSION}

The results obtained for the tests stated in the MATERIAL AND METHODS section are presented with the mean glandular dose calculations.

\subsection{Beam output repeatability and linearity}

In Tables 1-4 are showed the results of the tests of output repeatability and linearity for a certain current-time product.

Table 1: Results of output repeatability (\%) with the ionization chambers used in this work at $28 \mathrm{kV}$ and $\mathrm{Mo} / \mathrm{Mo}$

\begin{tabular}{ccccc}
\hline & \multicolumn{2}{c}{ GE Senographe DMR-plus } & \multicolumn{2}{c}{ Philips VMI Graph Mammo } \\
\cline { 2 - 5 } $\begin{array}{c}\text { Tube-current exposure } \\
\text { time product (mAs) }\end{array}$ & $\begin{array}{c}\text { Radcal } \\
10 X 5-6 \mathrm{M}\end{array}$ & HIC & $\begin{array}{c}\text { Radcal } \\
10 X 5-6 \mathrm{M}\end{array}$ & HIC \\
\hline $\mathbf{2 0}$ & 0.10 & 0.05 & 0.24 & 0.53 \\
$\mathbf{4 0}$ & 0.08 & 0.17 & 0.33 & 0.11 \\
$\mathbf{8 0}$ & 0.02 & 0.27 & 0.29 & 0.07 \\
\hline
\end{tabular}

Table 2: Output values obtained with the ionization chambers used in this work at $28 \mathrm{kV}$ and Mo/Mo for the GE Senographe DMR-plus mammography unit

\begin{tabular}{ccccc}
\hline Ionization & \multicolumn{3}{c}{$\mathbf{Y}^{\mathbf{a}}(\boldsymbol{\mu G y} / \mathbf{m A s})$} & Normalized output \\
\cline { 2 - 5 } chamber & $\mathbf{Y}_{\mathbf{1}}$ & $\mathbf{Y}_{\mathbf{2}}$ & $\mathbf{Y}_{\mathbf{3}}$ & $(\boldsymbol{\mu G y} / \mathbf{m A s}$ at 1 m $)$ \\
\hline Radcal 10X5-6M & $126.35 \pm 0.15$ & $127.01 \pm 0.05$ & $127.62 \pm 0.06$ & $44.97 \pm 0.02$ \\
HIC & $135.2 \pm 1.3$ & $135.4 \pm 1.3$ & $134.9 \pm 1.3$ & $47.86 \pm 0.07$ \\
\hline
\end{tabular}

${ }^{\mathrm{a}} \mathrm{Y}_{1}, \mathrm{Y}_{2}$, and $\mathrm{Y}_{3}$ are related to $20 \mathrm{mAs}, 40 \mathrm{mAs}$, and $80 \mathrm{mAs}$, respectively.

Table 3: Output values obtained with the ionization chambers used in this work at $28 \mathrm{kV}$ and Mo/Mo for the Philips VMI Graph Mammo mammography unit

\begin{tabular}{ccccc}
\hline Ionization & \multicolumn{3}{c}{$\mathbf{Y}^{\mathbf{a}}(\boldsymbol{\mu G} \mathbf{G} / \mathbf{m A s})$} & Normalized output \\
\cline { 2 - 5 } chamber & $\mathbf{Y}_{\mathbf{1}}$ & $\mathbf{Y}_{\mathbf{2}}$ & $\mathbf{Y}_{\mathbf{3}}$ & $(\boldsymbol{\mu G y} / \mathbf{m A s}$ at 1 m) \\
\hline Radcal 10X5-6M & $117.27 \pm 0.15$ & $117.96 \pm 0.10$ & $118.45 \pm 0.04$ & $42.44 \pm 0.04$ \\
HIC & $120.3 \pm 1.2$ & $120.7 \pm 1.2$ & $121.4 \pm 1.2$ & $43.50 \pm 0.02$ \\
\hline
\end{tabular}

${ }^{\mathrm{a}} \mathrm{Y}_{1}, \mathrm{Y}_{2}$, and $\mathrm{Y}_{3}$ are related to $20 \mathrm{mAs}, 40 \mathrm{mAs}$, and $80 \mathrm{mAs}$, respectively.

Table 4: Linearity with response $(L) . L_{1}$ is related to $Y_{1}$ and $Y_{2}$ and $L_{2}$ is related to $Y_{2}$ and $Y_{3}$

\begin{tabular}{ccccc}
\hline \multirow{2}{*}{$\begin{array}{c}\text { Ionization } \\
\text { chamber }\end{array}$} & \multicolumn{2}{c}{ GE Senographe DMR-plus } & \multicolumn{3}{c}{ Philips VMI Graph Mammo } \\
\cline { 2 - 5 } & $\mathbf{L}_{\mathbf{1}}$ & $\mathbf{L}_{\mathbf{2}}$ & $\mathbf{L} \boldsymbol{\text { L }})$ & $\mathbf{L}_{\mathbf{1}}$ \\
\hline Radcal 10X5-6M & 0.29 & 0.21 & 0.29 & 0.21 \\
HIC & 0.09 & 0.21 & 0.17 & 0.29 \\
\hline
\end{tabular}

According to the IAEA requirements for beam output repeatability test, the maximum variation should be $5 \%$ at a tube tension of $28 \mathrm{kV}$ and a Mo/Mo target-filter combination [6]. It can be noticed from Table 1 that $0.53 \%$ is the maximum variation of beam output repeatability test, calculated with the HIC for the Philips VMI Graph Mammo mammography system. Therefore all values obtained follow the IAEA limit for this test. 
The output values calculated with the measurements acquired with the ionization chambers tested in this investigation are showed in Table 2 and Table 3, for both mammography equipment utilized. It can be realized that the values associated with the HIC measurements were larger than the results of the Radcal ionization chamber with maximum variation of $7.0 \%$ for the output test related to the GE mammographic unit and $2.6 \%$ for the Philips mammographic unit. However, this discrepancy is not a problem because the output test results obtained with the HIC are within the IAEA requirements. The reason for this difference is under investigation, but the distinct geometric characteristics of both ionization chambers can be a strong factor to explain this behavior. A similar discrepancy was found with a Tandem ionization chamber [12].

To evaluate the output values of the mammography systems utilized in this work, the normalized output was calculated for $20 \mathrm{mAs}, 40 \mathrm{mAs}$, and $80 \mathrm{mAs}$ and the inverse square law correction was applied to acquire the output at $100 \mathrm{~cm}$ from the X-ray tube focus, as stated in IAEA HHS No 2 [6]. It can be seen in Table 2 and in Table 3 that the beam outputs obtained with the HIC measurements exceeds the acceptable tolerance for this test $(30 \mathrm{mGy} / \mathrm{mAs}$ at $100 \mathrm{~cm}$ for $28 \mathrm{kV}$ and $\mathrm{Mo} / \mathrm{Mo}$ ) [6]. The results are presented with their respective overall uncertainties with a coverage factor of 2 .

The results of the linearity test are presented in Table 4. All of them are lower than the maximum value of $10 \%$, for both mammography systems utilized in this work, as recommended in IAEA report [6]. It can be noticed that the linearity values related to the HIC measurements present a lower value of $0.09 \%$ for $\mathrm{L}_{1}$ for the GE Senographe DMR-plus mammography system and a higher value of $0.29 \%$ for $\mathrm{L}_{2}$ for the Philips VMI Graph Mammo, while the Radcal ionization chamber presents similar values for $\mathrm{L}_{1}$ and $\mathrm{L}_{2}$ for both equipment.

\subsection{Incident air kerma at the entrance surface of the PMMA slabs}

In Tables 5 and 6, the results of the incident air kerma at the entrance surface of the PMMA slabs are presented for the GE Senographe DMR-plus and for the Philips VMI Graph Mammo unit, respectively. The presented values for $\mathrm{K}_{\mathrm{i}, \mathrm{t}}$ were corrected for differences of the mAs used in automatic and manual modes, respectively, as stated in the IAEA TRS 457 [16].

As it can be seen in Tables 5 and 6, the maximum difference between the incident air kerma measured with the reference ionization chamber and the developed one was only $5.62 \%$ for the GE Senographe DMR-plus mammography unit and only $4.42 \%$ for the Philips VMI Graph Mammo mammography unit. The HIC presented higher values (except in the case of Table 5 for $20 \mathrm{~mm}$ PMMA thickness) than those of the Radcal ionization chamber.

Table 5: Incident air kerma obtained by the ionization chambers utilized in this work for various PMMA thicknesses. GE Senograph DMR-plus mammography unit

\begin{tabular}{cccccc}
\hline & \multicolumn{3}{c}{ Radiographic technique } & \multicolumn{2}{c}{$\mathbf{K}_{\mathrm{i}, \mathrm{t}}(\mathbf{m G y})$} \\
\cline { 2 - 6 } $\begin{array}{c}\text { PMMA thickness } \\
(\mathbf{m m})\end{array}$ & $\begin{array}{c}\text { Target/filter } \\
\text { combination }\end{array}$ & $\mathbf{k V}$ & $\mathbf{m A s}$ & $\begin{array}{c}\text { Radcal } \\
\mathbf{1 0 X 5 - 6 M}\end{array}$ & HIC \\
\hline 20 & $\mathrm{Mo} / \mathrm{Mo}$ & 25 & 20.0 & $1.253 \pm 0.061$ & $1.229 \pm 0.012$ \\
45 & $\mathrm{Mo} / \mathrm{Mo}$ & 28 & 100.0 & $9.505 \pm 0.010$ & $10.071 \pm 0.098$ \\
60 & $\mathrm{Mo} / \mathrm{Rh}$ & 30 & 125.0 & $12.737 \pm 0.013$ & $13.42 \pm 0.13$ \\
80 & $\mathrm{Rh} / \mathrm{Rh}$ & 32 & 200.0 & $25.490 \pm 0.026$ & $26.77 \pm 0.26$ \\
\hline
\end{tabular}


Table 6: Incident air kerma obtained by the ionization chambers utilized in this work for various PMMA thicknesses. Philips VMI Graph Mammo mammography unit

\begin{tabular}{cccccc}
\hline & \multicolumn{2}{c}{ Radiographic technique } & \multicolumn{2}{c}{$\mathbf{K}_{\mathrm{i}, \mathrm{t}}(\mathbf{m G y})$} \\
\cline { 2 - 6 } $\begin{array}{c}\text { PMMA } \\
\text { thickness (mm) }\end{array}$ & $\begin{array}{c}\text { Target/filter } \\
\text { combination }\end{array}$ & $\mathbf{k V}$ & $\mathbf{m A s}$ & $\begin{array}{c}\text { Radcal } \\
\mathbf{1 0 X 5 - 6 M}\end{array}$ & HIC \\
\hline 20 & $\mathrm{Mo} / \mathrm{Mo}$ & 22 & 35.0 & $1.328 \pm 0.068$ & $1.375 \pm 0.015$ \\
45 & $\mathrm{Mo} / \mathrm{Mo}$ & 28 & 118.0 & $11.256 \pm 0.012$ & $11.56 \pm 0.11$ \\
60 & $\mathrm{Mo} / \mathrm{Rh}$ & 30 & 125.0 & $14.195 \pm 0.014$ & $14.84 \pm 0.14$ \\
80 & $\mathrm{Mo} / \mathrm{Rh}$ & 32 & 175.0 & $25.997 \pm 0.026$ & $27.20 \pm 0.26$ \\
\hline
\end{tabular}

\subsection{Half-value layer results}

In Tables 7 and 8 are showed the results for the HVL measurements, for anode/filter combinations that are chosen by the mammography systems automatic exposure control and for exposure of different thicknesses of PMMA. For tube tensions of $22 \mathrm{kV}, 25 \mathrm{kV}$, and $28 \mathrm{kV}$ the anode-filter combination of Mo/Mo was used, and for $30 \mathrm{kV}$ and $32 \mathrm{kV}, \mathrm{Mo} / \mathrm{Rh}$. It can be noticed that the HVL results obtained with the ionization chambers tested in this work are proportional with the tube tension and they agreed with international recommendations [6].

Table 7: Half-value layer results with the ionization chambers used in this work. GE Senographe DMR-plus mammography unit

\begin{tabular}{ccc}
\hline \multirow{2}{*}{$\begin{array}{c}\text { Tube voltage } \\
(\mathbf{k V})\end{array}$} & Radcal & HVL $(\mathbf{m m A l})$ \\
& $\mathbf{1 0 X 5 - 6 \mathbf { M }}$ & HIC \\
\hline $\mathbf{2 5}$ & 0.33 & 0.33 \\
$\mathbf{2 8}$ & 0.37 & 0.36 \\
$\mathbf{3 0}$ & 0.44 & 0.43 \\
$\mathbf{3 2}$ & 0.48 & 0.48 \\
\hline
\end{tabular}

Table 8: Half-value layer results with the ionization chambers used in this work. Philips VMI Graph Mammo mammography unit

\begin{tabular}{ccc}
\hline \multirow{2}{*}{$\begin{array}{c}\text { Tube voltage } \\
(\mathbf{k V})\end{array}$} & Radcal & HVL $(\mathbf{m m A l})$ \\
\cline { 2 - 3 } & $\mathbf{1 0 X 5 - 6 \mathbf { M }}$ & HIC \\
\hline $\mathbf{2 2}$ & 0.29 & 0.31 \\
$\mathbf{2 8}$ & 0.37 & 0.37 \\
$\mathbf{3 0}$ & 0.43 & 0.43 \\
$\mathbf{3 2}$ & 0.45 & 0.45 \\
\hline
\end{tabular}

\subsection{Mean glandular dose determination}

The $\mathrm{D}_{\mathrm{G}}$ was calculated using Equation 6 and the $\mathrm{K}_{\mathrm{i}, \mathrm{t}}$ values presented in Tables 5 and 6 . The product of $g_{t}$ and $c_{t}$ conversion coefficients is related to the HVL values obtained with the ionization chambers, and it was obtained by interpolation of the data from the IAEA HHS No 17 [15]. In Figure 3, the interpolation curves and the regression expressions are presented for the 
PMMA thicknesses used in this work. The uncertainty was less than $0.05 \%$, not visible in the graphs.
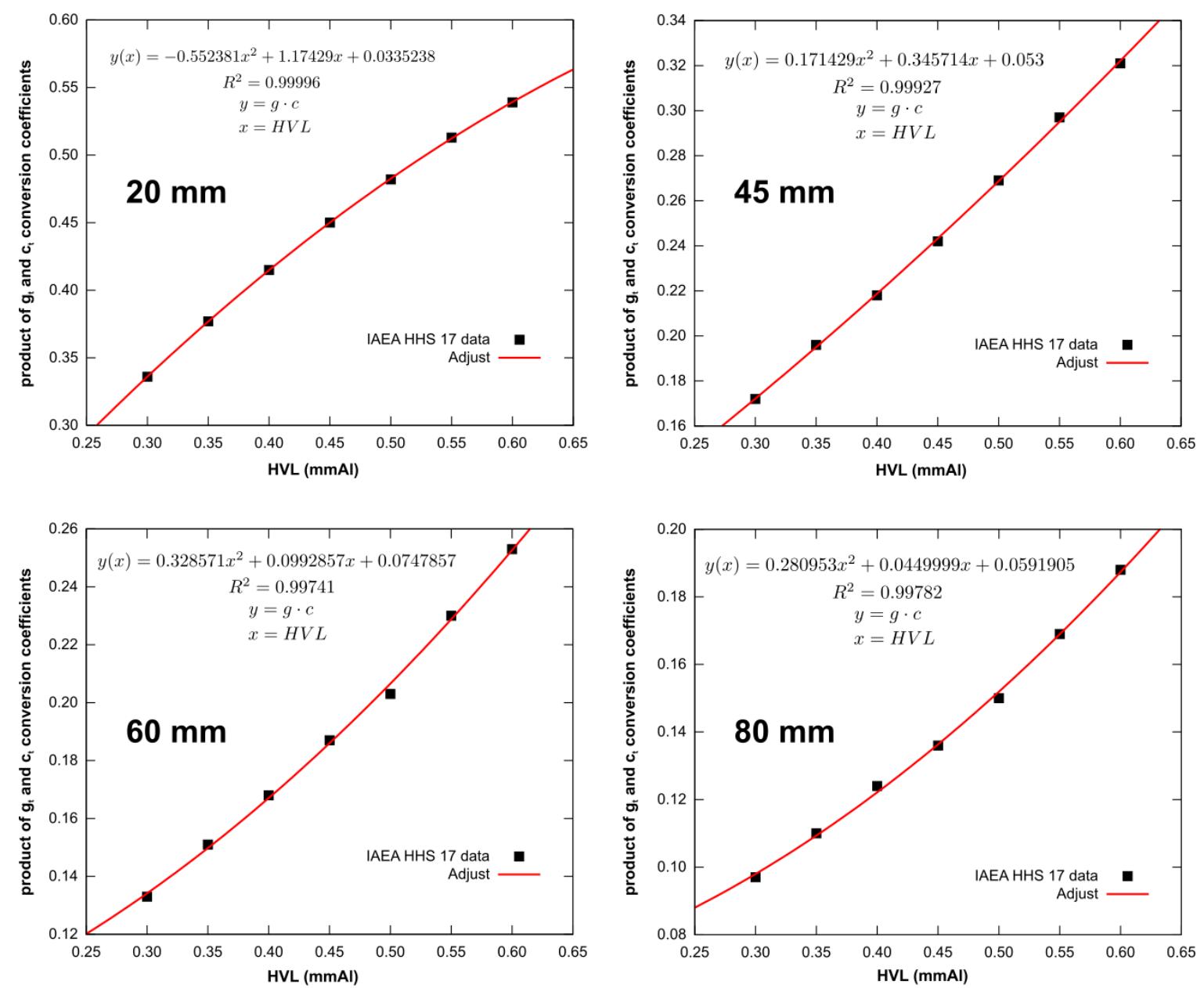

Figure 3: Interpolation curves to obtain the product of $g_{t}$ and $c_{t}$ conversion coefficients for each PMMA thickness utilized in this work $(20 \mathrm{~mm}, 45 \mathrm{~mm}, 60 \mathrm{~mm}$, and $80 \mathrm{~mm})$

Table 9: The product between $g_{t}$ and $c_{t}$ conversion coefficients for each PMMA thickness utilized in this work

\begin{tabular}{|c|c|c|c|c|}
\hline \multirow{3}{*}{$\begin{array}{c}\text { PMMA } \\
\text { thickness } \\
(\mathbf{m m})\end{array}$} & \multicolumn{4}{|c|}{ product of $g_{t}$ and $c_{t}$ conversion coefficients } \\
\hline & \multicolumn{2}{|c|}{ GE Senograph DMR plus } & \multicolumn{2}{|c|}{ Philips VMI Graph Mammo } \\
\hline & $\begin{array}{c}\text { Radcal } \\
\text { 10X5-6M }\end{array}$ & HIC & $\begin{array}{c}\text { Radcal } \\
\text { 10X5-6M }\end{array}$ & HIC \\
\hline 20 & 0.360 & 0.361 & 0.329 & 0.342 \\
\hline 45 & 0.202 & 0.202 & 0.204 & 0.203 \\
\hline 60 & 0.181 & 0.179 & 0.180 & 0.179 \\
\hline 80 & 0.146 & 0.146 & 0.135 & 0.135 \\
\hline
\end{tabular}


Table 10: Mean glandular dose values in function of the PMMA thickness utilized in this work

\begin{tabular}{ccccc}
\hline \multirow{2}{*}{$\begin{array}{c}\text { PMMA } \\
\text { thickness }\end{array}\left(\begin{array}{cccc}\text { GE } \\
\right.$\cline { 2 - 5 }\end{array}} & \multicolumn{2}{c}{ GE Senograph DMR plus } & \multicolumn{2}{c}{ Philips VMI Graph Mammo } \\
\cline { 2 - 5 } & $\begin{array}{c}\text { Radcal } \\
\text { 10X5-6M }\end{array}$ & HIC & $\begin{array}{c}\text { Radcal } \\
\text { 10X5-6M }\end{array}$ & HIC \\
\hline $\mathbf{2 0}$ & $0.451 \pm 0.025$ & $0.444 \pm 0.004$ & $0.437 \pm 0.024$ & $0.519 \pm 0.005$ \\
$\mathbf{4 5}$ & $1.920 \pm 0.002$ & $2.029 \pm 0.020$ & $2.296 \pm 0.002$ & $2.347 \pm 0.023$ \\
$\mathbf{6 0}$ & $2.341 \pm 0.002$ & $2.447 \pm 0.024$ & $2.592 \pm 0.003$ & $2.695 \pm 0.026$ \\
$\mathbf{8 0}$ & $3.944 \pm 0.004$ & $4.139 \pm 0.040$ & $3.729 \pm 0.004$ & $3.907 \pm 0.030$ \\
\hline
\end{tabular}

Table 11: Mean glandular dose values in relation to the PMMA thickness of $20 \mathrm{~mm}, 45 \mathrm{~mm}, 60 \mathrm{~mm}$ and $70 \mathrm{~mm}$ (adapted from IAEA HHS No 17 [15])

\begin{tabular}{cccc}
\hline $\begin{array}{c}\text { PMMA } \\
\text { thickness } \\
(\mathbf{m m})\end{array}$ & $\begin{array}{c}\text { Thickness of } \\
\text { equivalent breast } \\
(\mathbf{m m})\end{array}$ & $\begin{array}{c}\text { Maximum acceptable } \\
\text { level for } \mathbf{D}_{\mathbf{G}} \\
(\mathbf{m G y})\end{array}$ & $\begin{array}{c}\text { Maximum desirable } \\
\text { level for } \mathbf{D}_{\mathbf{G}} \\
(\mathbf{m G y})\end{array}$ \\
\hline $\mathbf{2 0}$ & 21 & 1.0 & 0.6 \\
$\mathbf{4 5}$ & 53 & 2.5 & 2.0 \\
$\mathbf{6 0}$ & 75 & 4.5 & 3.6 \\
$\mathbf{7 0}$ & 90 & 6.5 & 5.1 \\
\hline
\end{tabular}

In Table 9 the product of $g_{t}$ and $c_{t}$ conversion coefficients obtained for the HVL values calculated from the measurements taken with the ionization chambers utilized in this work are presented.

According to the IAEA HHS No 17 [15], the s factor values are 1.000 for the Mo/Mo anodefilter combination and 1.017 for $\mathrm{Mo} / \mathrm{Rh}$. In Table 10 the $\mathrm{D}_{\mathrm{G}}$ values obtained with the measurements from the ionization chambers utilized in this work are presented. The reference acceptable and desired levels recommended for $\mathrm{D}_{\mathrm{G}}$ by IAEA [15] are presented in Table 11.

It can be seen by comparison between the values from Tables 10 and 11 that the values for $D_{G}$ obtained with the measurements of the ionization chambers utilized in this work are within the levels recommended by IAEA [15], for both mammography units tested. The $\mathrm{D}_{\mathrm{G}}$ values varied with the anode-filter material utilized and with the PMMA thickness. The increasing X-ray attenuation with increasing PMMA thickness implies in higher $\mathrm{D}_{\mathrm{G}}$ values starting with the minimum related to $20 \mathrm{~mm}$ PMMA thickness.

The $\mathrm{D}_{\mathrm{G}}$ level for PMMA thickness of $80 \mathrm{~mm}$ is not presented in the IAEA HHS No 17 [15], but the obtained values relative to this PMMA thickness are lower than the ones relative to the $70 \mathrm{~mm}$ PMMA thickness, as can be seen by comparison between Tables 10 and 11, even considering the uncertainty of the measurements.

\section{CONCLUSIONS}

The current work aimed to quantify the incident air kerma and the HVL of two distinct mammography systems with a homemade ionization chamber and to calculate the mean glandular dose for various PMMA thicknesses. A breast phantom developed at IPEN according to international recommendations [16] was utilized.

The homemade ionization chamber presented an excellent performance in incident air kerma and HVL measurements for the various radiographic techniques utilized in this work. It was possible to calculate the mean glandular doses, with the appropriate conversion factors/coefficients.

All the results presented good agreement when compared to those acquired with a commercial ionization chamber, except the ones related to the output values in which the HIC results were 
higher than the Radcal ionization chamber. The results obtained with the HIC measurements were within the IAEA mammography unit quality control specifications [6, 15]. So, the HIC may be applied for dosimetric tests as the ones presented in this work, and it may be used in a quality control program at mammography clinics and hospitals.

\section{ACKNOWLEDGEMENTS}

The authors are thankful to the Brazilian agencies CNPq (Grants No. 304789/2011-9 and No. 141915/2009-9), and MCTI (INCT for Radiation Metrology in Medicine Grant No. 573659/20087), for partial financial support.

\section{REFERENCES}

1. Meghzifene A, Dance DR, McLean D, Kramer H-M. Dosimetry in diagnostic radiology. Eur. J. Radiol. 2010;76:11-14, doi: 10.1016/j.ejrad.2010.06.032

2. UNSCEAR. SOURCES AND EFFECTS OF IONIZING RADIATION: Report to the General Assembly with Scientific Annexes, Annex A. United Nations Scientific Committee on the Effects of Atomic Radiation. Vol. 1, New York, 2008.

3. Ferlay J, Soerjomataram I, Dikshit R, Eser S, Mathers C, Rebelo M, Parkin DM, Forman D, Bray F. Cancer incidence and mortality worldwide: Sources, methods and major patterns in GLOBOCAN 2012. Int. J. Cancer. 2015;136:E359-E386, doi: 10.1002/ijc.29210

4. INCA. Estimate/2016 - Cancer Incidence in Brazil. Instituto Nacional de Câncer José Alencar Gomes da Silva. Vol. 1, Rio de Janeiro, 2015.

5. Dance DR, Young KC, van Engen RE. Further factors for the estimation of mean glandular dose using the United Kingdom, European and IAEA breast dosimetry protocols. Phys. Med. Biol. 2009;54:43614372, doi: 10.1088/0031-9155/54/14/002

6. IAEA. Quality Assurance Programme for Screen Film Mammography. International Atomic Energy Agency. IAEA Human Health Series No 2. Vienna, 2009.

7. ICRU. Patient dosimetry for X-rays used in medical imaging. International Commission on Radiation Units and Measurements. Report 74. Bethesda, 2005.

8. Neves LP, Perini AP, Caldas LVE. A new standard cylindrical graphite-walled ionization chamber for dosimetry in ${ }^{60} \mathrm{Co}$ beams at calibration laboratories. Radiat. Phys. Chem. 2014;104, 235-239, doi: 10.1016/j.radphyschem.2014.04.003

9. Nonato FBC, Sakuraba RK, Cruz JC, Caldas LVE. Characterization tests of a new parallel plate ionization chamber for use in electron beams. Rad. Phys. Chem. 2014;104:244-247, doi: 10.1016/j.radphyschem.2014.06.011

10. Perini AP, Neves LP, Caldas LVE. 2014. Investigation of the applicability of a special parallel-plate ionization chamber for X-ray beam dosimetry. Rad. Phys. Chem. 2014;95:94-97, doi: 10.1016/j.radphyschem.2013.03.006

11. Silva JO, Nonato FBC, Caldas LVE. Characterization tests of a homemade ionization chamber in mammography standard radiation beams. Rad. Phys. Chem. 2014;95:151-153, doi: 10.1016/j.radphyschem.2013.03.009

12. Silva JO, Corrêa EL, Vivolo V, Potiens MPA, Caldas LVE. Quality Control Tests in a Mammographic Unit Using a Homemade Ionization Chamber. IEEE Trans. Nucl. Sci. 2013;60: 708-711, doi: 10.1109/TNS.2012.2216548

13. Corrêa EL, Silva JO, Vivolo V, Potiens MPA, Daros KAC, Medeiros RB. Intensity variation study of the radiation field in a mammographic system using thermoluminescent dosimeters TLD-900 ( $\mathrm{CaSO}_{4}$ :Dy). Rad. Phys. Chem. 2014;95:116-118, doi: 10.1016/j.radphyschem.2013.03.010

14.Corrêa EL. Quality control methodology and implementation of X-radiation standards beams, mammography level, following IEC 61267 standard [dissertation]. São Paulo (SP):University of São Paulo; 2010. 134 p. In Portuguese.

15. IAEA. Quality Assurance Programme for Digital Mammography. International Atomic Energy Agency. IAEA Human Health Series No 17. Vienna, 2011.

16. IAEA. Dosimetry in diagnostic radiology: an international code of practice. International Atomic Energy Agency. IAEA Technical Reports Series No 457. Vienna, 2007.

17. Dance DR, Skinner CL, Young KC, Beckett JR, Kotre CJ. Additional factors for the estimation of mean glandular breast dose using the UK mammography dosimetry protocol. Phys. Med. Biol. 2000;45: 3225-3240. 
18. Dance DR. Monte Carlo calculation of conversion factors for the estimation of mean glandular breast dose. Phys. Med. Biol. 1990;35:1211-1219. 